\title{
Beryllium-boron relative sensitivity factors for melilitic glasses measured with a NanoSIMS ion microprobe
}

\author{
Kohei Fukuda, ${ }^{1 *}$ Wataru Fujiya, ${ }^{2}$ Hajime HiYagon, ${ }^{1}$ Yoshiki Makino, ${ }^{4}$ NaOji Sugiura,,${ }^{1}$ Naoto TaKahata, ${ }^{3}$ \\ TAKAFUMI HIRATA ${ }^{4}$ and YUJI SANO ${ }^{3}$ \\ ${ }^{1}$ Department of Earth and Planetary Science, The University of Tokyo, Bunkyo-ku, Tokyo 113-0033, Japan \\ ${ }^{2}$ College of Science, Ibaraki University, Mito, Ibaraki 310-8512, Japan \\ ${ }^{3}$ Atmosphere and Ocean Research Institute, The University of Tokyo, Kashiwa, Chiba 277-8564, Japan \\ ${ }^{4}$ Geochemical Research Center, The University of Tokyo, Bunkyo-ku, Tokyo 113-0033, Japan
}

(Received June 25, 2017; Accepted November 26, 2017)

\begin{abstract}
The short-lived radionuclide ${ }^{10} \mathrm{Be}\left(t_{1 / 2}=1.4 \mathrm{Myr}\right)$ present in the Early Solar System (ESS) provides important information about the astrophysical environment in which the solar system formed. However, the origin of ${ }^{10} \mathrm{Be}$ in the ESS remains controversial. To reveal its origin, it is important to determine precise and accurate ${ }^{10} \mathrm{Be}$ abundances in meteoritic components. The initial ${ }^{10} \mathrm{Be} /{ }^{9} \mathrm{Be}$ ratio can be estimated using ion microprobe analysis and a ${ }^{10} \mathrm{~B} /{ }^{11} \mathrm{~B}-{ }^{9} \mathrm{Be} /{ }^{11} \mathrm{~B}$ correlation. The relative sensitivities for $\mathrm{Be}$ and $\mathrm{B}$ must be determined to obtain ${ }^{9} \mathrm{Be} /{ }^{11} \mathrm{~B}$ ratios of unknowns. Here, we report $\mathrm{Be} / \mathrm{B}$ relative sensitivities for synthetic melilitic glasses and silica-rich NIST SRM 610 glass measured with a NanoSIMS ion microprobe. The Be/B relative sensitivities for melilitic glasses are identical to that of the NIST 610 glass within uncertainties, which suggests that the matrix effects, at least between the NIST 610 glass and melilite, are not significant with respect to Be-B measurements. The present results confirm that the observed variations in the ${ }^{10} \mathrm{Be} /{ }^{9} \mathrm{Be}$ ratios for $\mathrm{CV}$ calcium-aluminum-rich inclusions (CAIs) are real and the origin of ${ }^{10} \mathrm{Be}$ must be attributed to irradiation by the active early sun. It is also inferred that the ${ }^{10} \mathrm{Be} /{ }^{9} \mathrm{Be}$ ratios of fractionation and unidentified nuclear effect (FUN) CV CAIs are not significantly lower than those for normal (non-FUN) CV CAIs, suggesting similar formation conditions.
\end{abstract}

Keywords: secondary ion mass spectrometry, Berrylium-10, relative sensitivity, melilite, early solar system

\section{INTRODUCTION}

Beryllium-10, which decays to ${ }^{10} \mathrm{~B}$ with a half-life of 1.4 Myr (Korschinek et al., 2010), cannot be produced by thermonuclear reactions in stars but by spallation reactions induced by galactic and/or stellar cosmic rays (e.g., McKeegan et al., 2000; Desch et al., 2004). Previous Be-B measurements on calcium-aluminum-rich inclusions (CAIs), which are believed to be the earliest solids in the Early Solar System (ESS; Amelin et al., 2010), have demonstrated that this short-lived radionuclide was present in the ESS with initial ${ }^{10} \mathrm{Be} /{ }^{9} \mathrm{Be}$ ratios ranging from $1.3 \times 10^{-4}$ to $1.0 \times 10^{-2}$ (McKeegan et al., 2000; Sugiura et al., 2001; MacPherson et al., 2003; Chaussidon et al., 2006; Liu et al., 2010; Wielandt et al., 2012; Srinivasan and Chaussidon, 2013; Gounelle et al., 2013; Dunham et al., 2016, 2017; Liu et al., 2017; Sossi et al., 2017). However, the origin of ${ }^{10} \mathrm{Be}$ in the ESS is unknown. Several mechanisms have been suggested for the origin of ${ }^{10} \mathrm{Be}$ including enhanced trapping of galactic cosmic

\footnotetext{
*Corresponding author (e-mail: k.fukuda@eps.s.u-tokyo.ac.jp)
}

Copyright (c) 2018 by The Geochemical Society of Japan. rays (GCRs) in the collapsing cloud core (Desch et al., 2004), solar cosmic ray irradiation (e.g., McKeegan et $a l ., 2000)$, and stellar processes with neutrino reactions in a relatively low-mass supernova (Banerjee et al., 2016). Varying initial ${ }^{10} \mathrm{Be}$ abundances in CAIs indicate heterogeneous production and/or distribution of ${ }^{10} \mathrm{Be}$ in the ESS, preferring local production of ${ }^{10} \mathrm{Be}$ near the protosun.

Most of the Be-B measurements using secondary ion mass spectrometry (SIMS) have been performed on melilite (solid solution between gehlenite, $\mathrm{Ca}_{2} \mathrm{Al}_{2} \mathrm{SiO}_{7}$, and åkermanite, $\mathrm{Ca}_{2} \mathrm{MgSi}_{2} \mathrm{O}_{7}$ ) in CAIs into which Be preferentially partitions (Lauretta and Lodders, 1997). With respect to SIMS measurements, the ${ }^{9} \mathrm{Be}^{+} /{ }^{11} \mathrm{~B}^{+}$relative sensitivity factor [RSF: defined by $\left({ }^{9} \mathrm{Be}^{+} /{ }^{11} \mathrm{~B}^{+}\right)_{\text {SIMS }} /\left({ }^{9} \mathrm{Be} /\right.$ $\left.{ }^{11} \mathrm{~B}\right)_{\text {TRUE }}$ ] of melilite is necessary to calculate the $\mathrm{Be} / \mathrm{B}$ ratios using ${ }^{10} \mathrm{~B} /{ }^{11} \mathrm{~B}$ vs. ${ }^{9} \mathrm{Be} /{ }^{11} \mathrm{~B}$ (isochron) diagrams. In previous studies, the RSF for melilite has been assumed to be the same as that of silica-rich glasses such as the NIST SRM 610 glass (e.g., MacPherson et al., 2003). However, the chemical composition of these standards is considerably different from that of melilite and the abovementioned assumption might therefore be invalid. Thus, previously reported initial ${ }^{10} \mathrm{Be} /{ }^{9} \mathrm{Be}$ ratios may include serious systematic errors. For example, a significant dif- 


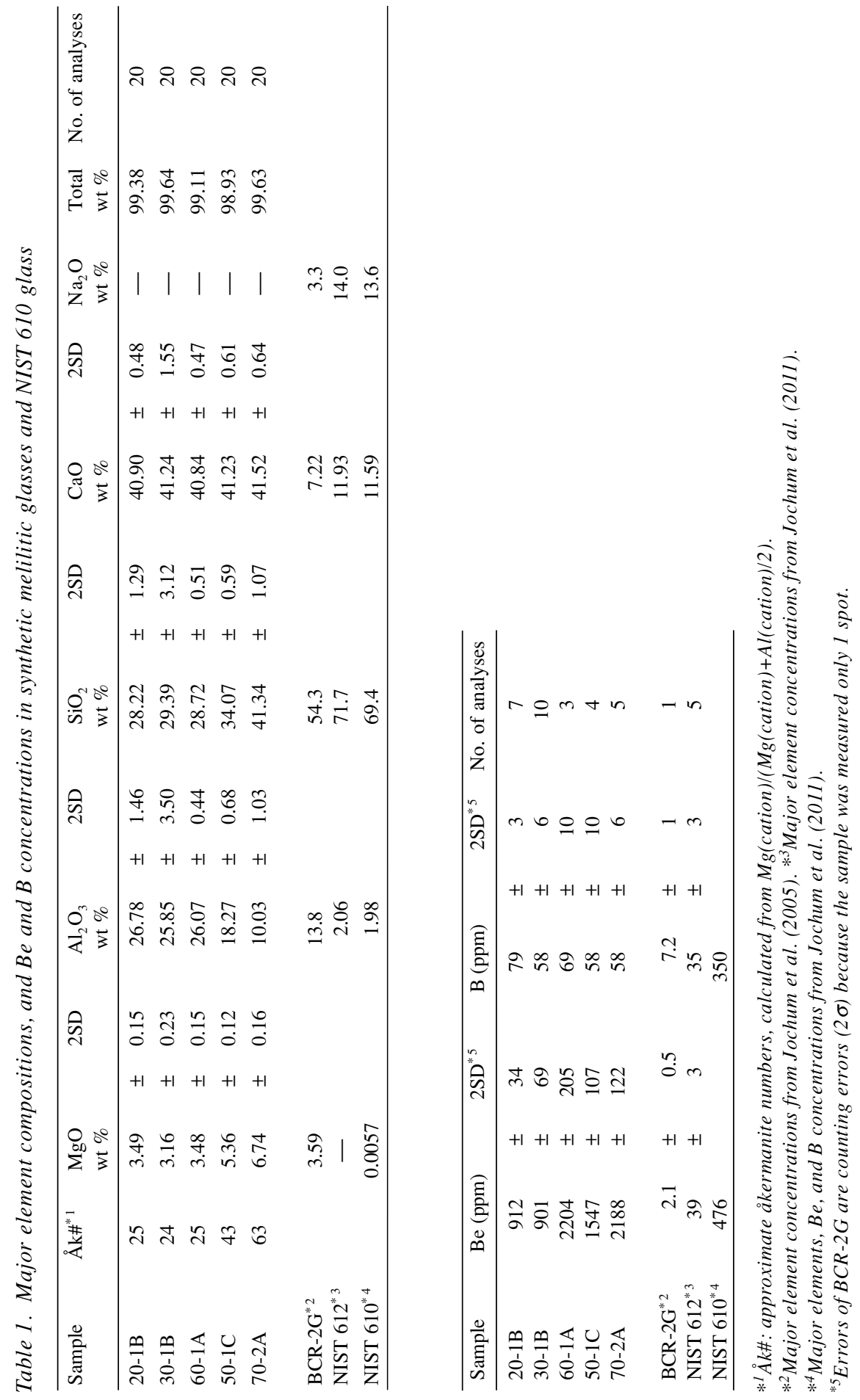


Table 2. Ion intensity ratios measured with the NanoSIMS and the calculated relative sensitivity factors

\begin{tabular}{|c|c|c|c|c|c|c|c|c|c|c|c|c|}
\hline \multirow{2}{*}{$\begin{array}{l}\text { Sample } \\
20-1 B\end{array}$} & \multirow{2}{*}{$\begin{array}{l}\stackrel{\AA}{\mathrm{k} \# \#} \\
25\end{array}$} & \multicolumn{3}{|c|}{$\begin{array}{c}{ }^{9} \mathrm{Be} /{ }^{11} \mathrm{~B} \text { atomic ratios } \\
\text { (atomic ratio)*2 }\end{array}$} & \multirow{2}{*}{$\begin{array}{c}\text { No. of analyses } \\
7\end{array}$} & \multicolumn{3}{|c|}{$\begin{array}{c}{ }^{9} \mathrm{Be}^{+} /{ }^{11} \mathrm{~B}^{+} \\
\text {(ion intensity ratio)*3 }\end{array}$} & \multirow{2}{*}{$\begin{array}{c}\text { No. of analyses } \\
4\end{array}$} & \multicolumn{3}{|c|}{$\mathrm{RSF}^{* 1}$} \\
\hline & & 17.3 & \pm & 0.6 & & 44.3 & \pm & 2.2 & & 2.57 & \pm & 0.16 \\
\hline $30-1 \mathrm{~B}$ & 24 & 23.3 & \pm & 1.6 & 10 & 57.6 & \pm & 2.9 & 4 & 2.47 & \pm & 0.21 \\
\hline $60-1 \mathrm{~A}$ & 25 & 48.2 & \pm & 6.9 & 3 & 135.9 & \pm & 6.9 & 3 & 2.82 & \pm & 0.43 \\
\hline $50-1 \mathrm{C}$ & 43 & 40.4 & \pm & 4.8 & 4 & 100.0 & \pm & 11.3 & 4 & 2.48 & \pm & 0.40 \\
\hline $70-2 \mathrm{~A}$ & 63 & 56.4 & \pm & 4.6 & 5 & 145.9 & \pm & 11.5 & 4 & 2.59 & \pm & 0.30 \\
\hline weighted mean & & & & & & & & & & 2.55 & \pm & 0.11 \\
\hline NIST 610 & & 2.03 & & & & 4.98 & \pm & 0.25 & 11 & 2.44 & \pm & 0.12 \\
\hline
\end{tabular}

ference in the Mn/Cr RSF was observed between silicates and carbonates, which resulted in significant errors in the Mn-Cr ages for carbonates (Sugiura et al., 2010; Fujiya et al., 2012; Steele et al., 2017). Preliminary results for $\mathrm{Be} / \mathrm{B}$ RSFs for three melilitic glasses were presented by Fukuda et al. (2016). Note that the reported Be/B RSFs in Fukuda et al. (2016) are not absolute values because we did not check relative sensitivities between each electron multiplier (EM) during the analysis. In the present study, we conducted more refined measurements on five newly synthesized melilitic glasses using a NanoSIMS (for $\mathrm{Be}^{+} / \mathrm{B}^{+}$intensity ratios) and a laser ablation-inductively coupled plasma-mass spectrometer (LA-ICP-MS; for $\mathrm{Be} / \mathrm{B}$ elemental ratios). We report the revised RSFs, which are essential for the determination of accurate initial abundances of ${ }^{10} \mathrm{Be}$ and to discuss its origin in the ESS.

\section{EXPERIMENTAL}

We synthesized five glasses with approximate melilitic compositions and åkermanite numbers (Åk\#s; see Table 1 for the definition) ranging from 24 to 63 that were doped with trace amounts of $\mathrm{Be}$ and $\mathrm{B}$ with varying $\mathrm{Be} / \mathrm{B}$ ratios (Table 1). The glasses were prepared by melting mixtures of oxide powders. The starting materials were wrapped in Pt-foil, heated, melted with a blowtorch, and quenched by dropping them into Milli-Q water. The synthesized glasses $\left(\sim 500 \times 500 \mu \mathrm{m}^{2}\right)$ were embedded in epoxy together with a NIST SRM 610 glass standard and then polished. The sample mount was cleaned with Mill-Q water and ethanol to remove surface contamination. The sample was coated with carbon after drying to prevent surface charge during subsequent electron microprobe and SIMS analyses.

The major element concentrations of the synthetic glasses were determined with a JXA-8530F field-emission gun electron microprobe installed at the University of Tokyo using a $15 \mathrm{kV}$ accelerating voltage, $12 \mathrm{nA}$ beam current, $\sim 1 \mu \mathrm{m}$ focused beam, and wavelength-dispersive $\mathrm{X}$-ray spectroscopy (WDS). Matrix effects were corrected using the ZAF method. The concentrations of major elements in the synthesized glasses are listed in Table 1. The approximate Åk\#s and Be and B concentrations measured with LA-ICP-MS are also shown.

The ion intensities of $\mathrm{Be}$ and $\mathrm{B}$ were determined with a NanoSIMS 50 ion probe at the Atmosphere and Ocean Research Institute (AORI) of the University of Tokyo. The NanoSIMS measurements were performed in multicollection mode. $\mathrm{A}^{16} \mathrm{O}^{-}$primary ion beam $(\sim 1 \mathrm{nA}$ intensity and $\sim 5 \mu \mathrm{m}$ in diameter) was rastered over $10 \times 10$ $\mu \mathrm{m}^{2}$ areas $(32 \times 32$ pixels with a dwell time of $200 \mu \mathrm{s} /$ pixel) to stabilize the secondary ion intensities. To remove the carbon coating and surface contamination before each analysis, a $\sim 1 \mathrm{nA}$ primary ion beam was rastered over $10 \times 10 \mu \mathrm{m}^{2}$ areas for $\sim 10 \mathrm{~min}$. Secondary ions of ${ }^{9} \mathrm{Be}^{+},{ }^{10} \mathrm{~B}^{+},{ }^{11} \mathrm{~B}^{+}$, and ${ }^{30} \mathrm{Si}^{+}$were then detected simultaneously with secondary electron multipliers (EMs). The measurements were performed with a mass resolving power (MPR) of 1500 at a peak height of $1 \%$. The intensities of ${ }^{9} \mathrm{Be}^{+},{ }^{11} \mathrm{~B}^{+}$, and ${ }^{30} \mathrm{Si}^{+}$were $(2.1-3.8) \times 10^{4}$ cps, $(0.3-6.0) \times 10^{3} \mathrm{cps}$, and $(0.1-1.7) \times 10^{5} \mathrm{cps}$, respectively. An electronic beam blanking mode was applied such that only signals from the central $24 \times 24$ pixel area were collected. This blanking helped to avoid contributions from scattered ions from the surroundings. The relative sensitivities between the EMs used for the Be and B measurements were checked after the measurement and corrected to calculate RSFs. The dead time ( $44 \mathrm{~ns})$ of the counting system was also corrected. The EM background (much lower than $\sim 0.05 \mathrm{cps}$ ) was not corrected because it was negligible compared with the count rates of ${ }^{9} \mathrm{Be}$ and ${ }^{11} \mathrm{~B}$ for the samples. Measurements on synthetic melilitic glasses were conducted only near the center of the individual glasses.

After the NanoSIMS analyses, the Be and B concen- 
trations near NanoSIMS analysis spots on the same glasses were determined using a LA-ICP-MS. Laser ablation was performed with an in-house laser ablation system (Cyber Probe) combined with a titanium-sapphire (Ti:S) femtosecond laser (IFRIT, Cyber Laser, Japan) and galvano metric fast scanning laser system (Yokoyama et al., 2011; Makino et al., 2017). A single quadrupole mass spectrometer (iCAP Qc, Thermo Fisher Scientific, USA) was utilized. The LA-ICP-MS measurements were performed in spot analysis mode. We obtained ion intensities for ${ }^{7} \mathrm{Li}^{+},{ }^{9} \mathrm{Be}^{+},{ }^{10} \mathrm{~B}^{+},{ }^{11} \mathrm{~B}^{+},{ }^{24} \mathrm{Mg}^{+},{ }^{29} \mathrm{Si}^{+}$, and ${ }^{43} \mathrm{Ca}^{+}$. Ablation pits of $\sim 25 \mu \mathrm{m}$ in diameter were produced by fast circular scanning of a laser beam with a diameter of 10 $\mu \mathrm{m}$. The scanning repetition rate and laser fluence were optimized to obtain maximum signal intensities for ${ }^{238} \mathrm{U}$ and ${ }^{11} \mathrm{~B}$ using NIST SRM 610 as a standard. The NIST 610 glass was also used as reference for the correction of the relative sensitivities of $\mathrm{Be}, \mathrm{B}$, and $\mathrm{Ca}$. The $\mathrm{Be}$ and $\mathrm{B}$ concentrations were determined using the observed ${ }^{9} \mathrm{Be}^{+} /$ ${ }^{43} \mathrm{Ca}^{+}$and ${ }^{11} \mathrm{~B}^{+} /{ }^{43} \mathrm{Ca}^{+}$intensity ratios and ${ }^{43} \mathrm{Ca}$ concentrations (calculated from total $\mathrm{Ca}$ concentrations assuming normal isotopic ratios) of the samples. The NIST SRM 612 and BCR-2G glasses were measured as secondary standards. The instrumentation and detailed analytical conditions are summarized in Supplementary Table S1.

\section{RESULTS}

The $\mathrm{Be}$ and $\mathrm{B}$ concentrations in the melilitic glasses obtained from LA-ICP-MS analyses are listed in Table 1. To verify the accuracy of the Be and B concentrations in the melilitic glasses, we also measured NIST 612 and BCR-2G glasses as secondary standards under the same analytical conditions. The $\mathrm{Be}$ and $\mathrm{B}$ concentrations of the NIST 612 and BCR-2G glasses are consistent with literature values (Jochum et al., 2011; Jacob, 2006), which justifies the current LA-ICP-MS analysis (see Table 1).

The ${ }^{9} \mathrm{Be} /{ }^{11} \mathrm{~B}$ atomic ratios (calculated from the $\mathrm{Be}$ and $\mathrm{B}$ concentrations in Table 1$),{ }^{9} \mathrm{Be}^{+} /{ }^{11} \mathrm{~B}^{+}$ion intensity ratios measured with the NanoSIMS, and corresponding Be/ B RSFs calculated for individual glasses are listed in Table 2. Figure 1 shows the ${ }^{9} \mathrm{Be}^{+} /{ }^{11} \mathrm{~B}^{+}$intensity ratios as a function of atomic ${ }^{9} \mathrm{Be} /{ }^{11} \mathrm{~B}$ ratios. The ${ }^{9} \mathrm{Be}^{+} /{ }^{11} \mathrm{~B}^{+}$intensity ratios and atomic ${ }^{9} \mathrm{Be} /{ }^{11} \mathrm{~B}$ ratios of the synthesized glasses correlate well. The RSFs calculated for individual glasses are identical within uncertainties $(2.47 \pm 0.21$ to $2.82 \pm 0.43)$. Note that five glasses have different chemical compositions, with Ak\# ranging from 24 to 63. The obtained RSFs are independent of the åkermanite numbers. Therefore, we used the weighted mean of the five datapoints and obtained the RSF of $2.55 \pm 0.11(2 \sigma)$. We also determined the Be/B RSF for NIST SRM 610 under the same analytical conditions. The RSF shows a small day-to-day variation from $2.44 \pm 0.12$ (2 standard devia-

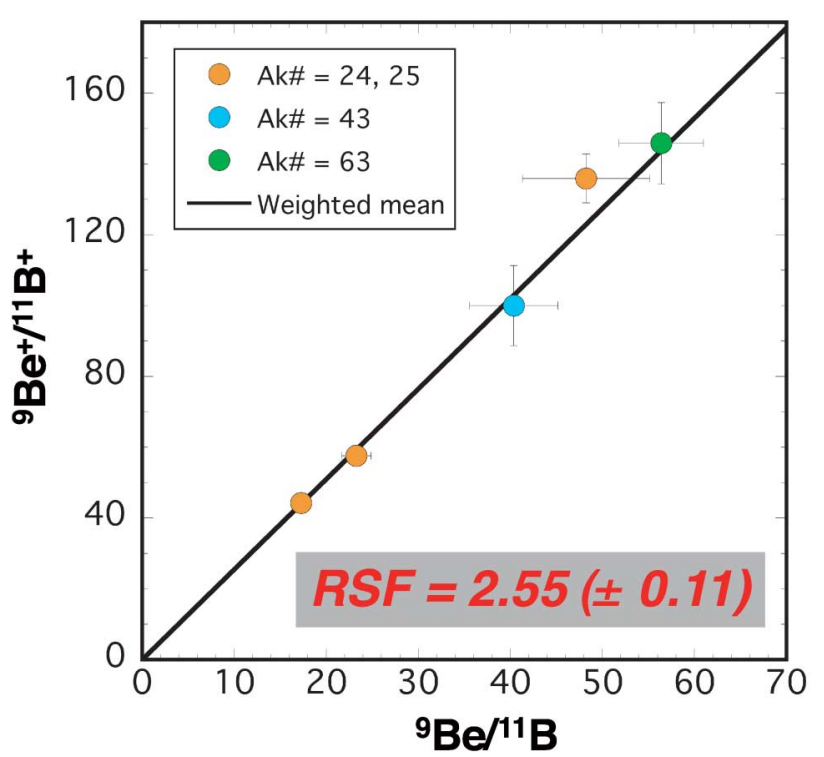

Fig. 1. ${ }^{9} \mathrm{Be}^{+} /{ }^{11} \mathrm{~B}^{+}$ratios as a function of Be/B atomic ratios determined on five synthetic melilitic glasses. The sensitivity difference between the electron multipliers (EMs) for ${ }^{9} \mathrm{Be}^{+}$and ${ }^{11} B^{+}$was corrected. The error bars represent 2 standard deviations $(S D)$ evaluated from repeated measurements of individual glasses. The slope defines the weighted mean value of the relative sensitivity of five glasses.

tions, SD) to $2.68 \pm 0.05$ (2 SD), but the RSF of our melilitic glasses obtained during the analytical period is $2.44 \pm 0.12$ ( $2 \mathrm{SD}$ ). The present results demonstrate that the Be/B RSF of the synthetic melilitic glasses is identical to that of NIST SRM 610, within uncertainties.

We also determined the RSFs of ${ }^{9} \mathrm{Be} /{ }^{30} \mathrm{Si}$ and ${ }^{11} \mathrm{~B} /{ }^{30} \mathrm{Si}$ for melilitic glasses and NIST 610 . The $\mathrm{Be} / \mathrm{Si}$ and $\mathrm{B} / \mathrm{Si}$ RSFs obtained for melilitic glasses are slightly higher than or almost comparable to those of the NIST 610 glass. These observations suggest matrix effects between melilitic glasses and NIST 610 glass, at least for some elements. Therefore, it may be fortuitous that the $\mathrm{Be} / \mathrm{B}$ RSF does not show noticeable matrix effects between melilitic glasses and NIST 610 glass. Detailed information is reported in Supplementary Materials (Table S2 and Fig. S1).

\section{Discussion}

The present results demonstrate that matrix effects do not significantly affect the relative ionization efficiencies of Be and B of the melilitic glasses and NIST 610 glass standard. Hence, the NIST 610 (and 612) glass can be used as a proper standard for accurate Be-B SIMS measurements on melilite in CAIs. Below, we will compare 


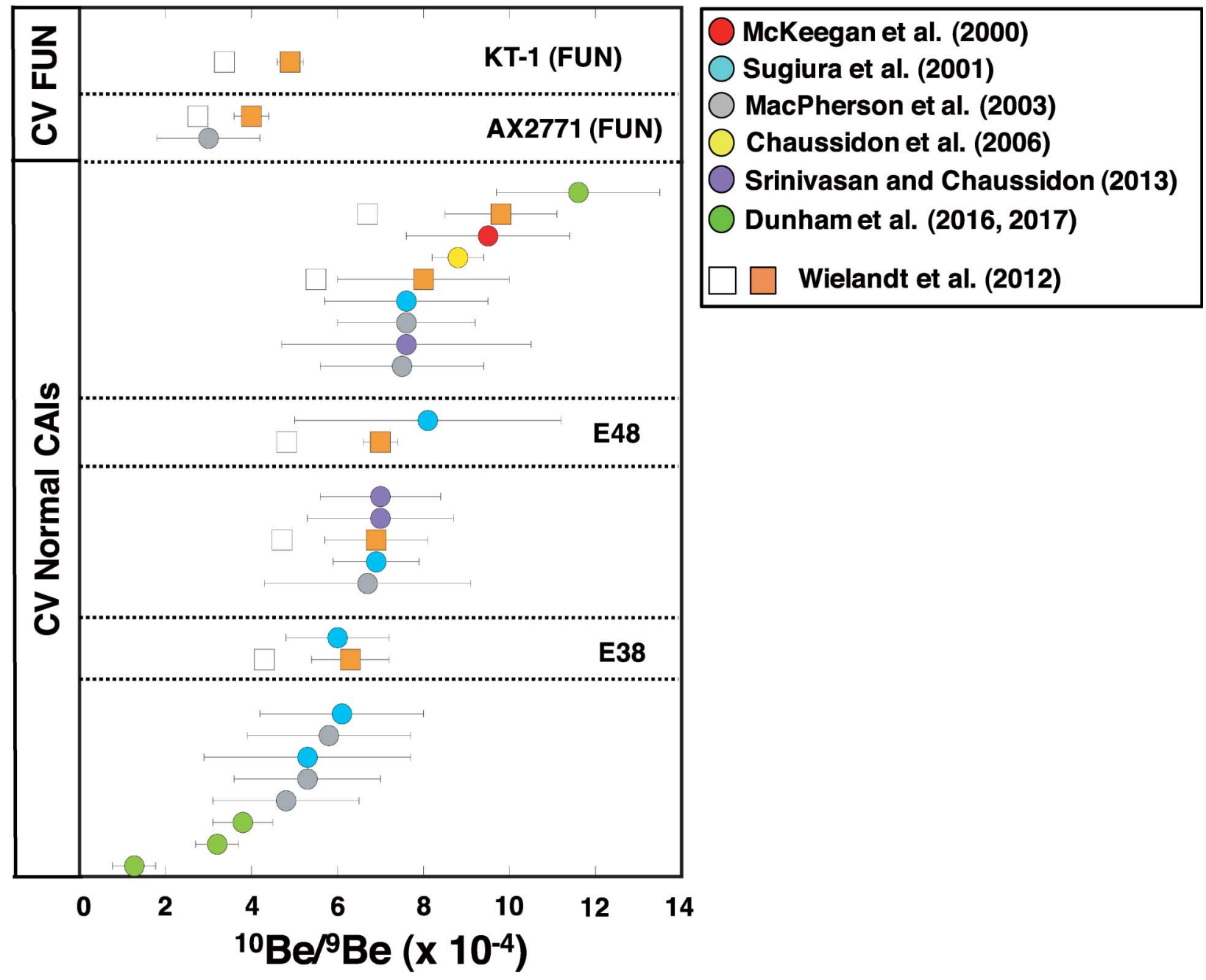

Fig. 2. Compilation of the reported initial ${ }^{10} \mathrm{Be} /{ }^{9} \mathrm{~B}$ e ratios of $\mathrm{CV}$ normal and fractionation and unidentified nuclear effect (FUN) CAIs (filled circles: McKeegan et al., 2000; Sugiura et al., 2001; MacPherson et al., 2003; Chaussidon et al., 2006; Srinivasan and Chaussidon, 2013; Dunham et al., 2016, 2017; open squares: Wielandt et al., 2012). The revised initial ${ }^{10}$ Be ${ }^{9}$ Be ratios (filled squares) are also plotted based on the RSF of the NIST 612 reported by Wielandt et al. (2012; see text). The error bars represent $2 \sigma$.

Be-B data previously reported for CV CAIs that were obtained using different standards. If necessary, we will apply appropriate corrections based on the present results.

MacPherson et al. (2003) and Dunham et al. (2016, 2017) used the NIST (NBS) 610 and 612 standards to determine the $\mathrm{Be} / \mathrm{B}$ RSF and reported initial ${ }^{10} \mathrm{Be} /{ }^{9} \mathrm{Be}$ ratios of CV CAIs including a few fractionation and unidentified nuclear effect (FUN) CAIs. The initial ${ }^{10} \mathrm{Be} /{ }^{9} \mathrm{Be}$ ratios vary from $1.3 \times 10^{-4}$ to $11.6 \times 10^{-4}$ for normal (i.e., non-FUN) CAIs and $3.0 \pm 1.2 \times 10^{-4}$ (MacPherson et al. 2003 ) or $<5.8 \times 10^{-4}$ (Dunham et al., 2017) for FUN CAIs. No corrections are needed for these data.

Sugiura et al. (2001) and Wielandt et al. (2012) conducted Be-B measurements on the same CAIs (E38 and E48) from Efremovka. However, the ${ }^{10} \mathrm{Be} /{ }^{9} \mathrm{Be}$ ratios re- ported by Sugiura et al. $\left(2001 ; 6.1 \pm 1.2 \times 10^{-4}\right.$ and $8.1 \pm$ $3.1 \times 10^{-4}$, respectively) are higher than those reported by Wielandt et al. $\left(2012 ; 4.43 \pm 0.61 \times 10^{-4}\right.$ and $4.82 \pm$ $0.25 \times 10^{-4}$, respectively). Wielandt et al. (2012) determined a $\mathrm{Be} / \mathrm{B}$ RSF of $\sim 2.6$ using the NIST SRM glass $612\left(\mathrm{SiO}_{2}=71.8 \mathrm{wt} \%\right.$; Jochum et al., 2011 $)$ and $\sim 1.78$ using GSC-1G and GSD-1G glasses $\left(\mathrm{SiO}_{2}=52.5 \mathrm{wt} \%\right.$ and $53.0 \mathrm{wt} \%$, respectively; Jochum et al., 2005). The former is in good agreement with our RSFs for NIST glass 610 and melilitic glasses, but the latter is $30 \%$ lower than the RSF for our melilitic glasses. Wielandt et al. (2012) adopted the latter RSF, but the present results suggest that the former RSF may be appropriate for accurate Be-B measurements on melilites in CAIs. If we use 2.6 instead of 1.78 as the $\mathrm{Be} / \mathrm{B} \mathrm{RSF}$, the revised values $(6.3 \pm 0.9 \times$ 
$10^{-4}$ and $7.0 \pm 0.4 \times 10^{-4}$, respectively) are consistent with those obtained by Sugiura et al . (2001), within uncertainties.

Note that the Be/B RSFs for NIST 610 and 612 determined by three different instruments are similar to each other, i.e., 2.6 (IMS-1280; Wielandt et al., 2012), 2.5 (IMS-6f; MacPherson et al., 2003), and 2.44 (NanoSIMS; this study). This suggests that the relative sensitivities of Be and B do not depend much on the ion optics of the instruments but are more intrinsic to sputtering and ionization processes. In fact, Ito and Messenger (2016) also reported similar RSFs for rare earth elements determined by different instruments (IMS-3f, IMS4f, and NanoSIMS).

Sugiura et al. (2001) determined a Be/B RSF of 2.67 \pm 0.09 for a suite of geological standards with varying $\mathrm{SiO}_{2}$ contents (51.0-72.3 wt\%; Imai et al., 1995). Although Sugiura et al. (2001) did not measure the RSF of NIST glasses, a similar RSF was obtained for the NIST 610 and 612 glasses using the same instrument (IMS-6f; MacPherson et al., 2003). Hence, the ${ }^{10} \mathrm{Be} /{ }^{9} \mathrm{Be}$ ratios reported in Sugiura et al. (2001) may not need corrections. Note that our melilitic glasses and NIST 610 measured in this study also have varying $\mathrm{SiO}_{2}$ contents $(28.2-41.3 \mathrm{wt} \%$ and $69.4 \mathrm{wt} \%$, respectively). This suggests that the $\mathrm{Be} / \mathrm{B}$ RSF is rather insensitive to the $\mathrm{SiO}_{2}$ content.

McKeegan et al. (2000) and Chaussidon et al. (2006) used a synthetic GB4 glass standard $\left(\mathrm{SiO}_{2}=72.9 \mathrm{wt} \%\right.$; Gurenko et al., 2005) and measured Be-B isotopes in CV CAIs with an IMS-1270 ion microprobe. The Be/B RSF measured by Chaussidon et al. (2006) varies from 2.51 to 2.88 (with an average of 2.73 ), which overlaps with that of NIST glass standards determined by three different instruments, as described above. Therefore, these data may not need corrections. Recently, Sossi et al. (2017) also used the GB4 standard for the Be-B analysis of $\mathrm{CV}$ CAIs. However, their Be/B RSF ( 3.17) is significantly higher than that of GB4 determined by Chaussidon et al. (2006) or that of silica-rich NIST glasses obtained by other researchers (see above). The cause for this difference is uncertain but may be attributed to different analytical conditions. In this case, we cannot make proper corrections.

Figure 2 summarizes initial ${ }^{10} \mathrm{Be} /{ }^{9} \mathrm{Be}$ ratios previously reported for CV normal and FUN CAIs (filled symbols). The original data of Wielandt et al. (2012) are shown as open symbols and the corrected data, assuming a $\mathrm{Be} / \mathrm{B}$ RSF of 2.6, are displayed as filled symbols. Note that the data for FUN CAIs were relatively low $\left(2.8 \times 10^{-4}\right.$ to 3.4 $\times 10^{-4}$; Wielandt et al., 2012) before correction. However, they are much higher after correction $\left(4.0 \times 10^{-4}\right.$ to $\left.4.9 \times 10^{-4}\right)$. Based on the original data, Wielandt et al. (2012) and Tatischeff et al. (2014) suggested that the ${ }^{10} \mathrm{Be} /$ ${ }^{9} \mathrm{Be}$ ratios recorded on FUN CAIs represent the baseline level present in the protosolar molecular cloud. However, the corrected ${ }^{10} \mathrm{Be} /{ }^{9} \mathrm{Be}$ ratios of FUN CAIs are higher than that of the baseline level of the molecular cloud $(\sim 1.3 \times$ $10^{-4}$ to $3.4 \times 10^{-4}$; Tatischeff et al., 2014) and within the range of normal CV CAIs (see Fig. 2). Furthermore, Dunham et al. (2017) recently reported a very low ${ }^{10} \mathrm{Be} /$ ${ }^{9} \mathrm{Be}$ ratio of $1.27 \pm 0.50 \times 10^{-4}$ for a normal CV CAI (B4), that is, much lower than the corrected ${ }^{10} \mathrm{Be} /{ }^{9} \mathrm{Be}$ ratios of CV FUN CAIs. These observations indicate that the initial ${ }^{10} \mathrm{Be} /{ }^{9} \mathrm{Be}$ ratios of CV FUN CAIs cannot be explained by a baseline level of ${ }^{10} \mathrm{Be}$ abundances in the protosolar molecular cloud.

Previous studies indicated a large variation in the ${ }^{10} \mathrm{Be} /$ ${ }^{9} \mathrm{Be}$ ratios of CV CAIs, from 1.3 to $11.6 \times 10^{-4}$ (McKeegan et al., 2000; Sugiura et al., 2001; MacPherson et al., 2003; Chaussidon et al., 2006; Wielandt et al., 2012; Srinivasan and Chaussidon, 2013; Dunham et al., 2016, 2017). The present results confirm that most of the previous data may not need corrections. Hence, the variation in the ${ }^{10} \mathrm{Be} /$ ${ }^{9} \mathrm{Be}$ ratios of $\mathrm{CV}$ CAIs is real. Note that the data for other types of refractory inclusions, such as hibonite and grossite inclusions, also show a large variation in the ${ }^{10} \mathrm{Be} /$ ${ }^{9} \mathrm{Be}$ ratios, from $5.3 \times 10^{-4}$ to $100 \times 10^{-4}$ (Liu et al., 2010; Gounelle et al., 2013). These data, however, must be reevaluated because the Be/B RSFs for hibonite and grossite may, in principle, not be identical to those of melilite or NIST standard glasses, especially considering that hibonite and grossite are non-silicate minerals. The observed variation in the ${ }^{10} \mathrm{Be} /{ }^{9} \mathrm{Be}$ ratios suggests the local production of ${ }^{10} \mathrm{Be}$, which is consistent with the production of ${ }^{10} \mathrm{Be}$ by solar cosmic ray irradiation (e.g., McKeegan et al., 2000).

\section{Conclusions}

In this study, we synthetized five melilitic glasses and investigated the Be/B RSFs of these glasses using a NanoSIMS 50 and LA-ICP-MS. We found that the Be/B RSFs of melilitic glasses (1) are independent of the Åk\#; (2) identical to that for NIST 610 silica-rich glass, within uncertainties; and (3) after proper correction of previous data based on the present results, the revised ${ }^{10} \mathrm{Be} /{ }^{9} \mathrm{Be}$ ratios of $\mathrm{CV}$ FUN CAIs are higher and well within the range of ${ }^{10} \mathrm{Be} /{ }^{9} \mathrm{Be}$ ratios of $\mathrm{CV}$ normal CAIs. Hence, the ${ }^{10} \mathrm{Be} /{ }^{9} \mathrm{Be}$ ratios of $\mathrm{CV}$ FUN CAIs may not represent a baseline level of ${ }^{10} \mathrm{Be}$ abundances in the protosolar molecular cloud, suggesting similar formation processes of both FUN and normal (non-FUN) CAIs, possibly due to solar cosmic ray irradiation.

Acknowledgments-We thank K. Ichimura for his advice on the synthesis of melilitic glasses and T. Kagoshima for the support during NanoSIMS measurements. Constructive discussions with T. Iizuka are greatly appreciated. We also express our grati- 
tude to Dr. D. Nakashima, Dr. M. Ito, Dr. M.-C. Liu, and the handling editor $\mathrm{H}$. Yurimoto whose comments greatly improved the quality of the paper. This study was in part supported by a Grant-in-Aid of the Ministry of Education, Science, Sport, and Culture of Japanese government (No. 26400524 to H. H.).

\section{REFERENCES}

Amelin, Y., Kaltenbach, A., Iizuka, T., Stirling, C. H., Ireland, T. R., Petaev, M. and Jacobsen, S. B. (2010) U-Pb chronology of the solar system's oldest solids with variable ${ }^{238} \mathrm{U} /$ ${ }^{235}$ U. Earth Planet. Sci. Lett. 300, 343-350.

Banerjee, P., Qian, Y.-Z., Heger, A. and Haxton, W. C. (2016) Evidence from stable isotopes and ${ }^{10} \mathrm{Be}$ for solar system formation triggered by a low-mass supernova. Nat. Commun. 7, 13639.

Chaussidon, M., Robert, F. and McKeegan, K. D. (2006) Li and $\mathrm{B}$ isotopic variations in an Allende CAI: Evidence for the in situ decay of short-lived ${ }^{10} \mathrm{Be}$ and for the possible presence of the short-lived nuclide ${ }^{7} \mathrm{Be}$ in the early solar system. Geochim. Cosmochim. Acta 70, 224-245.

Desch, S. J., Connolly, H. C., Jr. and Srinivasan, G. (2004) An interstellar origin for the beryllium 10 in calcium-rich, aluminum-rich inclusions. Astrophys. J. 602, 528-542.

Dunham, E., Wadhwa, M., Simon, S. and Grossman, L. (2016) Beryllium-boron systematics of refractory inclusions in CR2 and CV3 chondrites: evidence for ${ }^{10}$ Be heterogeneity (abstract). Meteorit. Planet. Sci. 79, \#6222.

Dunham, E., Wadhwa, M. and Desch, S. J. (2017) Berylliumboron systematics of two distinctive CAIs from CV3 chondrites: the relatively pristine CAI B4 from NWA 6991 and the FUN CAI CMS-1 from Allende (abstract). LPSC 45, \#2523.

Fujiya, W., Sugiura, N., Hotta, H., Ichimura, K. and Sano, Y. (2012) Evidence for the late formation of hydrous asteroids from young meteoritic carbonates. Nat. Commun. 3, 627.

Fukuda, K., Fujiya, W., Hiyagon, H., Sugiura, N., Takahata, N. and Sano, Y. (2016) An ion microprobe study of Be-B isotope systematics in melilite-rich CAIs based on newly determined $\mathrm{Be} / \mathrm{B}$ relative sensitivity factors for melilitic glass (abstract). Meteorit. Planet. Sci. 79, \#6459.

Gounelle, M., Chaussidon, M. and Rollion-Bard, C. (2013) Variable and extreme irradiation conditions in the early solar system inferred from the initial abundance of ${ }^{10} \mathrm{Be}$ in Isheyevo CAIs. Astrophys. J. 763, L33.

Gurenko, A. A., Veksler, I. V., Meixner, A., Thomas, R., Dorfman, A. M. and Dingwell, D. B. (2005) Matrix effect and partitioning of boron isotopes between immiscible $\mathrm{Si}$ rich and $\mathrm{B}$-rich liquids in the $\mathrm{Si}-\mathrm{Al}-\mathrm{B}-\mathrm{Ca}-\mathrm{Na}-\mathrm{O}$ system: A SIMS study of glasses quenched from centrifuge experiments. Chem. Geol. 222, 268-280.

Imai, N., Terashima, S., Itoh, S. and Ando, A. (1995) Compilation of analytical data for minor and trace elements in seventeen GSJ geochemical reference samples, "igneous rock series". Geostandard Newslett. 19, 135-213.

Ito, M. and Messenger, S. (2016) Rare earth element measurements and mapping of minerals in the Allende CAI, 7R191, by NanoSIMS ion microprobe. Meteorit. Planet. Sci. 51,
$818-832$.

Jacob, D. E. (2006) High sensitivity analysis of trace elementpoor geological reference glasses by Laser Ablation-Inductively Coupled Plasma-Mass Spectrometry (LA-ICP-MS). Geostand. Geoanal. Res. 30, 221-235.

Jochum, K. P., Willbold, M., Raczek, I., Stoll, B. and Herwig, K. (2005) Chemical Characteristation of the USGS Reference Glasses GSA-1G, GSC-1G, GSD-1G, GSE-1G, BCR2G, BHVO-2G and BIR-1G Using EPMA, ID-TIMS, IDICP-MS and LA-ICP-MS. Geostand. Geoanal. Res. 29, 285302.

Jochum, K. P., Weis, U., Stoll, B., Kuzmin, D., Yang, Q., Raczek, I., Jacob, D. E., Stracke, A., Birbaum, K., Frick, D. A., Günther, D. and Enzweiler, J. (2011) Determination of reference values for NIST SRM 610-617 glasses following ISO guidelines. Geostand. Geoanal. Res. 35, 397-429.

Korschinek, G., Bergmaier, A., Faestermann, T., Gerstmann, U. C., Knie, K., Rugel, G., Wallner, A., Dillmann, I., Dollinger, G., Lierse von Gostomski, C., Kossert, K., Maiti, M., Poutivtsev, M. and Remmert, A. (2010) A new value for the half-life of ${ }^{10} \mathrm{Be}$ by Heavy-Ion Elastic Recoil Detection and liquid scintillation counting. Nucl. Instrum. Methods Phys. Res. B 268, 187-191.

Lauretta, D. S. and Lodders, K. (1997) The cosmochemical behavior of beryllium and boron. Earth Planet. Sci. Lett. 146, 315-327.

Liu, M.-C., Nittler, L. R., Alexander, C. M. O. and Lee, T. (2010) Lithium-beryllium-boron isotopic compositions in meteoritic hibonite: implications for origin of ${ }^{10} \mathrm{Be}$ and early solar system irradiation. Astrophys. J. 719, L99-L103.

Liu, M.-C., Han, J. and Brearley, A. (2017) The boron isotopic ratios of a fine-grained inclusion from the Allan Hills 77307 chondrite (CO3.0) (abstract). Meteorit. Planet. Sci. 80, \#6291.

MacPherson, G. J., Huss, G. R. and Davis, A. M. (2003) Extinct ${ }^{10} \mathrm{Be}$ in type A Calcium-Aluminum-rich inclusions from CV chondrites. Geochim. Cosmochim. Acta 67, 3165-3179.

Makino, Y., Ohara, S., Yamada, M., Mukoyama, S., Hattori, K., Sakata, S., Tanaka, Y., Suzuki, T., Shinohara, A., Matsukawa, T., Yokoyama, K. and Hirata, T. (2017) Quantitative elemental bioimaging protocol using femtosecondlaser ablation-ICP-mass spectrometry coupled with glass standard reference material. Metallomics-Recent Analytical Techniques and Applications, Springer, 93-106.

McKeegan, K. D., Chaussidon, M. and Robert, F. (2000) Incorporation of short-lived ${ }^{10} \mathrm{Be}$ in a Calcium-Aluminum-rich inclusion from the Allende meteorite. Science 289, 13341337.

Sossi, P. A., Moynier, F., Chaussidon, M., Villeneuve, J., Kato, C. and Gounelle, M. (2017) Early solar system irradiation quantified by linked vanadium and beryllium isotope variations in meteorites. Nat. Astron. 1, 0055.

Srinivasan, G. and Chaussidon, M. (2013) Constraints on ${ }^{10} \mathrm{Be}$ and ${ }^{41} \mathrm{Ca}$ distribution in the early solar system from ${ }^{26} \mathrm{Al}$ and ${ }^{10} \mathrm{Be}$ studies of Efremovka CAIs. Earth Planet. Sci. Lett. 374, 11-23.

Steele, R. C. J., Heber, V. S. and McKeegan, K. D. (2017) Matrix effects on the relative sensitivity factors for manganese and chromium during ion microprobe analysis of carbon- 
ate: Implications for early Solar System chronology. Geochim. Cosmochim. Acta 201, 245-259.

Sugiura, N., Shuzou, Y. and Ulyanov, A. (2001) Beryllium-boron and aluminum-magnesium chronology of calciumaluminum-rich inclusions in $\mathrm{CV}$ chondrites. Meteorit. Planet. Sci. 36, 1397-1408.

Sugiura, N., Ichimura, K., Fujiya, W. and Takahata, N. (2010) $\mathrm{Mn} / \mathrm{Cr}$ relative sensitivity factors for synthetic calcium carbonate measured with a NanoSIMS ion microprobe. Geochem. J. 44, e11-e16.

Tatischeff, V., Duprat, J. and de Séréville, N. (2014) Light-element nucleosynthesis in a molecular cloud interacting with a supernova remnant and the origin of beryllium-10 in the protosolar nebula. Astrophys. J. 796, 124 (20 pp.).

Wielandt, D., Nagashima, K., Krot, A. N. and Huss, G. R. (2012)
Evidence for multiple sources of ${ }^{10} \mathrm{Be}$ in the early solar system. Astrophys. J. 748, L25.

Yokoyama, T. D., Suzuki, T., Kon, Y. and Hirata, T. (2011) Determinations of rare earth element abundance and $\mathrm{U}-\mathrm{Pb}$ age of zircon using multispot laser ablation-inductively coupled plasma mass spectrometry. Anal. Chem. 83, 88928899.

\section{SUPPLEMENTARY MATERIALS}

URL (http://www.terrapub.co.jp/journals/GJ/archives/ data/52/MS510.pdf)

Figure S1

Tables $\mathrm{S} 1$ and $\mathrm{S} 2$ 